\title{
IGLESIA CATÓLICA, EDUCACIÓN Y LAICIDAD EN LA HISTORIA ARGENTINA
}

\author{
Germán Torres \\ Ceil-Conicet y Universidad Nacional de Quilmes, Argentina.
}

\section{$\cos 8$}

\section{IGREJA CATÓLICA, EDUCAÇÃO E LAICIDADE NA HISTÓRIA ARGENTINA}

\begin{abstract}
Resumo atores Igreja, Estado e sociedade civil em diferentes momentos históricos.

Palavras-chave: educação, Igreja Católica, laicidade, Argentina.

\section{CATHOLIC CHURCH, EDUCATION AND LAICITY IN ARGENTINEAN HISTORY}

O objetivo deste trabalho é analisar, em uma perspectiva histórica, a relação entre a lgreja Católica e o campo da educação pública na Argentina, tendo a laicidade como eixo conceitual. Supomos que as diferentes configurações da relação entre a Igreja e o Estado podem ser definidas seguindo as tensões sobre a governança da educação. Apresenta-se uma periodização que vai desde o período colonial até o início do século 21, pela qual identificamos as linhas de continuidade, tensões e rearticulações da laicidade educacional, bem como as estratégias dos

Abstract

The aim of this paper is to analyze, in a historical perspective, the relationship between Catholic Church and the field of public education in Argentina, taking laicity as a conceptual axis. We assume that the different configurations of the relationship between Church and State can be defined following the tensions over education governance. We present a periodization, ranging from the colonial period to the beginning of the $21^{\text {st }}$ century, through which we identify lines of continuity, tensions and re-articulations of educational laicity as well as strategies of the Church, state and civil society actors in different historical moments.

Key-words: education, Catholic Church, laicity, Argentina. 


\section{IGLESIA CATÓLICA, EDUCACIÓN Y LAICIDAD EN LA HISTORIA ARGENTINA}

Resumen

El objetivo de este trabajo es analizar en perspectiva histórica la relación entre la Iglesia católica y el campo de la educación pública en Argentina, tomando a la laicidad como eje conceptual. Se asume que las distintas configuraciones de la relación entre la Iglesia y el Estado pueden ser definidas siguiendo las tensiones por el gobierno de la educación. Se presenta una periodización, que va desde la etapa colonial hasta el comienzo del siglo 21, que permite identificar líneas de continuidad, tensiones y rearticulaciones de la laicidad educativa, así como estrategias de la Iglesia, actores estatales y de la sociedad civil en distintos momentos históricos.

Palabras-clave: educación, Iglesia católica, laicidad, Argentina.

\section{ÉGLISE CATHOLIQUE, L'ÉDUCATION ET LAÏCITÉ DANS LES L'HISTOIRE ARGENTINE}

Résumé

Le but de cet article est d'analyser, dans une perspective historique, la relation entre l'Eglise catholique et le domaine de l'éducation publique en Argentine, en prenant la laïcité comme un axe conceptuel. Nous supposons que les différentes configurations de la relation entre l'Église et l'État peuvent être définies suivant les tensions sur la gouvernance de l'éducation. Nous présentons une périodisation, allant de la période coloniale au début du $21^{\mathrm{e}}$ siècle, à travers laquelle nous identifions les lignes de continuité, de tensions et de ré-articulations de la laïcité éducative ainsi que les stratégies de l'Église, l'État et la société civile dans les différents moments historiques.

Mots-clé: éducation, Église catholique, laïcité, Argentine. 


\section{Introducción}

acia las últimas décadas del siglo 19, asentada sobre una frágil estructura institucional en el territorio nacional, la Iglesia católica argentina fue constituyendo su identidad en un terreno de disputas frente a las posturas liberales de las élites gobernantes del país. El proceso de conformación del Estado-nación supuso la movilización de la propia Iglesia así como de otras organizaciones civiles impulsadas por ella, con el objetivo de catolizar los espacios políticos de participación social y de producción cultural.

Puede pensarse que para emprender un análisis en perspectiva histórica de las relaciones entre el Estado y la Iglesia católica argentina tan sólo basta con delimitar las contingentes relaciones de poder entre el catolicismo predominante en la cúpula eclesiástica y el campo de la educación pública. Este trabajo toma precisamente esta premisa como punto de partida. No se trata solamente de indicar a la educación como una entre otras posibles dimensiones de análisis. Antes bien, en este trabajo se busca destacar el hecho de que la educación misma ha constituido un terreno de acción privilegiado en el cual la Iglesia católica argentina construyó su identidad como un actor social ineludible, expandiendo desde ese lugar preeminente en la definición de lo educativo sus pretensiones de injerencia en otros aspectos políticos y culturales del país.

Este foco de análisis ya fue marcado por otros trabajos centrados en las relaciones entre la Iglesia católica y la política en Argentina. Por ejemplo, en su lectura histórica de la presencia de la Iglesia en la historia del país, desde la conformación moderna del Estado hasta fines del siglo 20, Ghio señala que:

El conflicto sobre la educación religiosa reaparecerá con fuerza en distintos momentos de la agitada historia política argentina del siglo 20. La lucha por la llamada libertad de enseñanza, el derecho a poder optar por una educación confesional, permitirá a los católicos elaborar distintas estrategias destinadas a devolver a la Iglesia parte de la influencia perdida en el proceso de organización nacional. (Ghio, 2007, p. 21)

Otro ejemplo en esta misma línea de sentido es el de Caimari (2010), quien sostiene que durante el primer gobierno peronista "la educación era uno de los ámbitos donde los intereses de la Iglesia y el gobierno se cruzaban y uno de los pocos donde es posible seguir la continuidad de esta relación" (p. 139). De modo similar, Dri (1997) señala en relación al regreso a la democracia en 1983 que "el tema de la educación constituye el terreno privilegiado de las relaciones, sea de enfrentamiento o de negociación, entre la Iglesia y el Estado" (p. 85). Aunque centradas en coyunturas históricas distintas estos señalamientos pueden funcionar como un eje común de análisis. La puesta en relieve de las disputas por lo educativo como un elemento constitutivo de las estrategias y la identidad de la Iglesia frente a los distintos gobiernos fue adelantado por estos estudios.

Este trabajo pretende avanzar en esa línea, partiendo de una lectura convergente de las principales referencias bibliográficas dentro de la hHistoria de la Iglesia Católica, la Historia de la Educación y la Sociología de la Religión, rastreando allí y sintetizando los señalamientos a la intervención de la Iglesia en el ámbito educativo. La unificación de referencias dispersas pretende aportar a una lectura global de esa intervención aún no presente en la historiografía local. No se trata de emprender un estado de la cuestión acerca de las relaciones entre la Iglesia católica y la educación en Argentina, sino que se 
busca analizar esas relaciones en perspectiva histórica y en función de algunos elementos analíticos que permitan identificar líneas de continuidad y rupturas a lo largo de la vida política del país y de su sistema educativo. Para ello, tomamos fundamentalmente el concepto de laicidad como vía de entrada para el abordaje de la mutua conformación de la Iglesia católica y el campo de la educación pública argentina.

\section{Laicidad, secularización y educación}

Una primera cuestión a señalar es la distinción entre secularización y laicidad. En términos generales, la secularización hace referencia al "largo proceso social, simbólico y cultural de recomposición de las creencias con la consiguiente pérdida de poder de los especialistas religiosos" (Mallimaci, 2006, p. 71). Dentro de este proceso, Casanova (1994) identifica tres formas distintas y no necesariamente simultáneas de entender la secularización: como diferenciación de las esferas seculares - política, economía, ciencia respecto a las instituciones y normas religiosas; como el declive progresivo de las creencias y prácticas religiosas; y como marginación de la religión en la esfera privada. ${ }^{1}$

Si la secularización se presenta como un proceso cultural de tensión entre la religión y la sociedad en el que se pone en juego una fluctuante conformación de lo público, la laicidad remite las configuraciones normativas y los vínculos entre actores estatales y religiosos en torno a la construcción de las denominadas libertades modernas, tales como la libertad de conciencia y de expresión. En esta línea de sentido, Blancarte (2012) señala tres elementos centrales de la laicidad: el respeto a la libertad de conciencia, la autonomía de lo político frente a lo religioso y la garantía de igualdad y no discriminación.

Existe asimismo coincidencia en destacar el carácter histórico de la laicidad, de manera de concebirla como "un proceso más que una forma fija o acabada" (Blancarte, 2008a, p. 30), o en palabras de Poulat, de entender que "no es estática" y que se trata de comprenderla "a partir de las batallas de ideas que suscitó, las medidas de derecho que la instituyeron, los equilibrios de facto que se establecieron" (2012, p. 38). Precisamente, resulta interesante señalar en el contexto de este trabajo que el término laicidad surgió por primera vez en 1871 en medio de los debates por la enseñanza no confesional y sin instrucción religiosa en Francia (Blancarte, 2008b). Un último punto analítico que también se ha destacado es la necesidad de no circunscribir el análisis de los procesos de laicización a los términos estrictamente jurídicos, sino de incluir también la conformación de culturas políticas específicas como modus operandi de la dirigencia política (Esquivel, 2010a). De modo tal que se pueda emprender un abordaje socio-histórico-cultural que dé cuenta de la conformación de la laicidad en la trama de relaciones entre el Estado, la sociedad civil y los actores religiosos.

Para nuestro caso, resulta necesario entonces analizar el devenir de la laicidad en el sistema educativo argentino en una mirada histórica que aborde los vínculos entre la Iglesia católica y los distintos gobiernos, prestando atención a las disputas por el control del campo educativo y las consecuentes reformulaciones y restructuraciones de los lugares tanto de la Iglesia católica como del Estado en el espacio público. Para ello, se

1 Para una discusión sobre los usos, alcances y límites del concepto de secularización, cf. Casanova, (2012), Mallimaci (2008).

Hist. Educ. [Online]

Porto Alegre

v. 18

ก. 44

Set./dez. 2014

p. $165-185$ 
propone a continuación una periodización ${ }^{2}$ de esta relación que permita identificar líneas de continuidad, tensiones y rearticulaciones de la laicidad educativa en distintos momentos históricos.

\section{Iglesia, educación y laicidad en Argentina}

\section{0-1880: de la Colonia a la conformación de la Argentina}

Es inevitable no comenzar con una referencia al papel de las órdenes religiosas católicas como las primeras impulsoras de emprendimientos educativos en el periodo colonial. En el marco del Patronato iniciado por el papa Julio II en 1508, el objetivo que guiaba a los conquistadores era el desarrollo de la empresa evangelizadora y la implantación de la cristiandad española sobre las poblaciones indígenas. Las órdenes de mercedarios y franciscanos fueron las que iniciaron la evangelización sistemática en el actual territorio argentino. También otras órdenes contaban con espacios educativos propios, como los dominicos y los agustinos (Brito, 1992; Liboreiro, 1992). Los jesuitas marcaron especialmente su presencia desde fines del siglo 16, siguiendo el modelo de reducciones en distintas regiones del territorio. Además de estos emprendimientos, la apuesta educativa católica suponía la formación de su propio cuerpo de clérigos y de las élites locales. En 1621, los jesuitas fundan el Colegio Máximo en Córdoba, germen de la futura universidad. Ya en tiempos del Virreinato del Rio de la Plata, se funda en Buenos Aires el Real Colegio de San Carlos en 1772, a cargo de Juan Maciel, un destacado canónigo.

En el periodo independentista se consolida en un grupo de intelectuales porteños, tales como Mariano Moreno y Manuel Belgrano, la idea de conformar un sistema escolar público y gratuito. En los años siguientes, esta idea se trasladaría a las propuestas de muchos de los caudillos provinciales, como Estanislao López en Santa Fe, Juan Bustos en Córdoba o Justo José de Urquiza en Entre Ríos. Estas ideas contrastaron con las posturas tradicionalistas y antiliberales de caudillos como Facundo Quiroga en La Rioja o Juan Manuel de Rosas en Buenos Aires. Tras la batalla de Caseros, la misma Constitución Nacional de 1853 que promulgó el sostenimiento del culto católico, la obligatoriedad de que el presidente lo fuera y la conversión al catolicismo de los indígenas, en su artículo $5^{\circ}$ estableció que cada provincia dictaría una Constitución propia que asegurara, entre otras cuestiones, la educación primaria gratuita. En esta coyuntura de consolidación nacional se abrió un espacio para la realización de las ideas liberales de la denominada Generación del 37, particularmente los proyectos educativos de Domingo Sarmiento. Más allá de las discusiones al interior de ese grupo de intelectuales sobre el perfil pedagógico que predominaría, se consolidaba la idea de que "la Argentina tendría un sistema educativo escolarizado en el cual el Estado jugaría un rol principal" (Puiggrós, 2012, p. 75).

Sin embargo, cabe destacar las disimilitudes entre este ideario y otras propuestas dentro del territorio nacional. El ejemplo más notable es el denominado nacionalismo católico cordobés, que ya desde la década del 60 del siglo 19 se enfrentó a las reivindicaciones laicistas en la educación (Roitenburd, 1993). Esta postura fundada en un

${ }^{2}$ Existen periodizaciones de la configuración de la laicidad en la historia argentina (Di Stefano, 2011; Mallimaci, 2004) aunque centradas en amplios procesos socio-políticos donde no es posible marcar la especificidad de lo educativo.
Hist. Educ. [Online]
Porto Alegre
v. 18
ก. 44
Set./dez. 2014
p. $165-185$ 
sustrato hispánico-católico se extendió con fuerza también en las escuelas del noroeste del país. Se presentaba así una continuidad con el lugar privilegiado otorgado a la religión católica en las constituciones provinciales sancionadas luego de Caseros, en las que, pese al avance liberal, se impuso la obligatoriedad de la enseñanza religiosa.

La existencia de posturas disímiles en torno a la laicidad dentro del territorio argentino será uno de los rasgos que marcará la definición de lo educativo y el rol de la Iglesia en las décadas siguientes. Recién en este momento histórico de formación de la Argentina resulta pertinente hablar de la laicidad educativa en base a la construcción de libertades referidas a lo religioso entre el Estado y la Iglesia, si bien todavía esos dos actores no habían conformado y consolidado acabadamente sus perfiles institucionales. Por un lado, no había aún una estructura estatal nacional que pudiera sostener un sistema educativo público como hoy conocemos, sino que existía una proliferación dispar de establecimientos nacionales, otros a cargo de las provincias, de órdenes religiosas, así como de bibliotecas públicas y sociedades populares. Por otro lado, en esta época la Iglesia argentina constituía una institución débil, marcada por la acefalia en la mayoría de sus diócesis y por el notable decrecimiento de su cuerpo de clérigos.

\section{0-1930: avances y retrocesos de la laicidad educativa}

En el proceso de formación del Estado-nación argentina el catolicismo se vio obligado a reformular su lugar en la sociedad frente a actores del espacio público que cuestionaban y avanzaban sobre los ámbitos de acción que había ocupado hasta entonces. La propia institución eclesiástica inició un triple proceso de romanización, nacionalización y clericalización (Zanatta, 1996). Es decir que estrechó sus vínculos con el Vaticano, arraigó su lugar evangelizador en el territorio y la identidad nacional, y consolidó su ortodoxia doctrinaria dentro del espectro de actores católicos laicos. Pues en este periodo, además de las voces de los propios clérigos, emergió también un catolicismo militante a través de una prensa propiamente católica, organizaciones obreras y otras asociaciones de intelectuales católicos, que reaccionaron frente a las posturas liberales que proliferaban desde hacía décadas y que en momentos de definición de los rasgos del Estado y la identidad argentina, se volvían cruciales para la Iglesia. La unión orgánica entre "el ciudadano y el fiel" (Di Stéfano; Zanatta, 2009, p. 321) dejaba progresivamente de funcionar como supuesto fundante, abriendo el juego a una reestructuración del lugar de la institución eclesiástica en la nueva sociedad argentina.

Este proceso de secularización, que se articulaba con un aire de época fundado en las ideas del triunfo de la razón y el progreso indefinido, forzó a la lglesia argentina a consolidar su identidad mediante la diferenciación frente a aquellos elementos opuestos a su visión de la sociedad, la cultura y la política: la modernidad y el liberalismo. La postura antiliberal dominante en el catolicismo argentino era parte de la trama ideológica de la Iglesia romana, sustentada en la denuncia doctrinaria de Pio IX a los errores contemporáneos indicados en el Syllabus de 1864, entre los que se contaban las ideas de intervención y control estatal sobre la educación.

Desde fines del siglo 19, la disputa con el Estado por el control del campo educativo fue uno de los puntos definitorios no sólo de las tensas relaciones de la Iglesia con la política, sino de su propia identidad como institución activa dentro de las discusiones públicas por los sentidos de la cultura argentina. Junto al matrimonio civil, la estatización 
de los cementerios y del registro de los ciudadanos implementados por el presidente Julio Roca, el establecimiento de un sistema educativo nacional implicó para la Iglesia la dislocación del lugar que ocupaba en la sociedad.

El epicentro de las discusiones por el gobierno de la educación estuvo primeramente en el Congreso Pedagógico Sudamericano, iniciado en 1882 a partir de un decreto de Roca y que sirvió como antesala para la discusión y sanción de la ley n. 1.420 en 1884 . En ese evento, en el que participaron especialistas locales e internacionales del continente americano, estaban depositadas las máximas expectativas de la oligarquía liberal gobernante en relación a la construcción de un sistema educativo que funcionara como una de las columnas fundamentales de la estructura estatal-nacional que se esperaba consolidar. En el Congreso Pedagógico, los intelectuales católicos tuvieron una marcada presencia en los debates. Los temas discutidos incluyeron la libertad de enseñanza, el lugar que le cabía al Estado en la educación de los niños y la presencia de la religión en la educación pública. Precisamente, uno de los puntos críticos del evento estuvo dado por la moción de declarar que la educación común "es esencialmente católica" (Bravo, 1985, p. 21), lo que motivó que, tras encendidas discusiones, la asamblea dominada por una mayoría liberal resolviera suprimir el tema religioso de los debates y que los obispos participantes y demás representantes católicos se retiraran del evento.

Ciertamente, la cuestión religiosa y el lugar del Estado en la educación se harían otra vez presentes en los debates iniciados en 1883 en el Congreso de la Nación. Esos temas fueron los nudos más tensos en las sesiones parlamentarias que derivaron en la sanción de la ley n. 1.420. Si bien la obligatoriedad de la educación religiosa pudo ser resistida por los liberales laicistas, la cuestión religiosa y el lugar de la Iglesia no dejaron de estar presentes en el texto de la ley finalmente sancionada. La ley n. 1.420 fue reconocida y exaltada en ese entonces y a lo largo de todo el siglo 20 como la normativa que instituyó la educación obligatoria, gratuita y laica.

A la luz de los debates y del texto definitivo, resulta evidente que esa ley se correspondió más con un enérgico laicismo que con la laicidad propiamente dicha, siguiendo la distinción de Blancarte (2008b) entre, por un lado, un posicionamiento político crítico muchas veces anticlerical - laicismo - y, por el otro lado, una forma de legitimación social ajena a todo elemento religioso - laicidad. La disputa por la laicidad permaneció latente en su polémico artículo $8^{\circ}$ que instituía que la enseñanza religiosa "sólo podrá ser dada en las escuelas públicas por los ministros autorizados de los diferentes cultos, a los niños de su respectiva comunión, y antes o después de las horas de clase". Aunque el carácter laico de la educación no es mencionado en ninguno de los artículos de la ley, la exclusión explícita de la religión del mínimo curricular obligatorio significó para la Iglesia una derrota que pasaría desde entonces a alimentar su animado rechazo a toda propuesta educativa que tuviera a la centralidad del Estado y la laicidad como principios rectores. La ley n. 1.420 funcionó como un punto de anclaje ineludible en la memoria del discurso educativo, que se extendería como relato unificador a lo largo de todo el siglo 20.

Al lema de la educación obligatoria, gratuita y laica de una ley que sólo era aplicable a la Capital Federal y los Territorios Nacionales, ${ }^{3}$ debe enfrentarse la configuración de la

${ }^{3}$ La ley n. 1.532, de 1884, creó los territorios nacionales de Chaco, Formosa, Misiones, La Pampa, Neuquén, Río Negro, Chubut, Santa Cruz y Tierra del Fuego.
Hist. Educ. [Online]
Porto Alegre
v. 18
ก. 44
Set./dez. 2014
p. $165-185$ 
laicidad en otras prácticas educativas. Las resistencias a la ley n. 1.420, a nivel normativo, tuvieron su desarrollo heterogéneo en las provincias donde sí se incluyó la enseñanza obligatoria de la religión. Asimismo, en los años inmediatos a la sanción de esa normativa, se crearon nuevos colegios católicos, centrados en la formación de la clase dirigente, y se amplió la oferta educativa de algunas órdenes religiosas. En los años siguientes, la Iglesia argentina se concentró en la consolidación, unificación y disciplinamiento del conjunto de establecimientos educativos católicos.

El proceso de centralización institucional de un circuito educativo alternativo al estatal incluyó la aprobación de un "plan de enseñanza religiosa" destinado a "implantar una instrucción religiosa básica en todos los colegios y escuelas del país que se hallan en manos de la Iglesia" (Di Stéfano; Zanatta, 2009, p. 396), así como la creación en 1925 del Consejo Superior de Educación Católica - Consudec -, en tanto órgano que marcaría las directrices oficiales para las instituciones educativas católicas del país. En 1922 se crearon los Cursos de Cultura Católica, un espacio educativo que funcionó como un prolífero reducto para una intelectualidad católica nacionalista.

Además de este fortalecimiento del campo educativo católico, debe destacarse que incluso dentro del mismo sistema educativo nacional hubo posicionamientos no siempre coherentes con los principios de la ley n. 1.420, con medidas de resistencia por parte de actores católicos en distintas provincias del país (Tedesco, 2003). Siguiendo a Puiggrós, el embate liberal contra la presencia obligatoria de la religión en las escuelas públicas

[n]o implicó su restricción al ámbito privado. Por el contrario, su presencia se manifestó en la escuela pública en el propio discurso escolar, que incluyó elementos religiosos en los libros de texto, en los discursos de las Conferencias Pedagógicas, en disertaciones de los funcionarios y en la palabra cotidiana de muchos maestros. (1990, p. 41)

Este periodo fundante del sistema educativo nacional constituyó un proceso marcado por avances y retrocesos dispares y constantes reconfiguraciones de la laicidad educativa. Esa no sería sino la lógica dominante a lo largo del siglo 20. Emergieron desde ese entonces los principales sentidos y algunas de las estrategias que dominarían las disputas por lo educativo entre la Iglesia argentina y el Estado por décadas: la discusión por la libertad de enseñanza, las prerrogativas estatales, el lugar del catolicismo en la identidad nacional; así como la lucha por la inclusión de la educación religiosa, articulada con una búsqueda de consolidación del conjunto de instituciones escolares católicas como alternativa a la propuesta educativa estatal.

\section{0-1946: nación católica y educación religiosa}

En la década del 1930, la Iglesia argentina ya había avanzado en su consolidación institucional mediante la centralización y disciplinamiento del conjunto de actores eclesiales y laicos, además de la expansión de su presencia en el territorio nacional. En esta coyuntura se afianzó una concepción integralista del catolicismo tendiente a la construcción de un orden social católico (Mallimaci, 1988). Ello significó un florecimiento del lugar de la Iglesia católica en el espacio público, incluido claramente el ámbito educativo. Se trataba de una ofensiva que la Iglesia había esperado desde el embate liberal que había impulsado la organización del Estado y la construcción de una identidad nacional en las últimas décadas del siglo 19. 
El quiebre de lo que era leída como la hegemonía liberal y laica en la educación a nivel nacional tuvo como trasfondo la sucesión de golpes militares que se iniciaron con el encabezado por José Uriburu en 1930. El breve auge de la ley n. 1.420 - incluso a pesar de las disparidades regionales señaladas - tuvo su fin en este periodo. En este nuevo contexto, el campo educativo fue uno de los lugares preeminentes en los que la Iglesia vio fortalecida su posición en la sociedad argentina. Por caso, en 1936 se fundó la Federación de Maestros y Profesores Católicos que se sumó al Consudec como institución organizadora del campo educativo católico. Asimismo se consolidaron las escuelas católicas, mientras que la Iglesia no dejaba de reclamar y presionar a los distintos gobiernos por la inclusión obligatoria de la educación religiosa en la educación pública, como forma de "reconquista" educativa "en nombre de la catolicidad de la nación" (Di Stefano y Zanatta, 2009, p. 442). En este periodo, la prédica educativa del catolicismo local estuvo marcada por los preceptos antiliberales de la encíclica de Pio XI Divini Illius Magistri de 1929, centrada específicamente en la cuestión de la educación cristiana. En ese texto se sintetizaba como doctrina el primado de la Iglesia y luego de la familia en la misión educativa, dejando para el Estado la función de garantía y tutela de dicha misión.

El golpe de estado de los militares nacionalistas en junio de 1943 representó el afianzamiento de los vínculos entre las Fuerzas Armadas y la Iglesia, abriendo el lugar a la consolidación del mito de la nación católica (Zanatta, 1996) y la consecuente construcción de un dispositivo integralista de catolización de todas las esferas de la vida social y en contra de las amenazas del liberalismo y del socialismo (Mallimaci, 1988). Fue Gustavo Martínez Zubiría, el ministro de Justicia e Instrucción Pública del gral. Pedro Ramírez, quien inició el quiebre normativo con lo que más molestaba de las disposiciones de la ley n. 1.420, al decretar la obligatoriedad de la enseñanza de la religión católica en todas las escuelas primarias y secundarias del país. El decreto n. 18.411, de fines de 1943, se fundamentó en el señalamiento explícito de las aberraciones laicistas de aquella ley derivadas de su controvertido artículo $8^{\circ}$. Si bien esta normativa implicó un fuerte reconocimiento a la Iglesia, su aplicación supuso como contraparte la apertura de un espacio de control por parte del Estado sobre las actividades educativas de los católicos dentro de las escuelas (Bernetti; Puiggrós, 1993).

Desde esta época, la instauración del imaginario que vinculaba de manera esencial a la Iglesia y también a las Fuerzas Armadas con el entramado de la identidad argentina afianzó la legitimidad de aquella institución para intervenir activamente en la vida política, cultural y social del país. Ello permitió que la Iglesia viera hecho realidad su repetido reclamo por la obligatoriedad de la educación religiosa en el sistema educativo público. Las reivindicaciones de la Iglesia católica para el ámbito educativo, los avances obtenidos así como las tensiones y resistencias en torno a la laicidad que tuvieron lugar en este periodo, estarían todas condensadas en la experiencia educativa del peronismo y su compleja relación con la Iglesia.

\section{6-1955: el peronismo y la educación religiosa}

Los vaivenes en los vínculos entre la Iglesia católica y el gobierno de Juan Perón fueron en sintonía con las tensiones fluctuantes en torno a la cuestión educativa. En su campaña previa a las elecciones presidenciales de 1946, la cuestión de la religión como parte obligatoria de la educación pública entró en juego como uno de los elementos

Hist. Educ. [Online]

Porto Alegre

v. 18

ก. 44

Set./ dez. 2014

p. $165-185$ 
destacados para obtener el apoyo de la Iglesia católica. Fue así que la continuidad de la educación religiosa se convirtió en uno de los puntos de conexión entre el peronismo y la institución eclesiástica, al menos al inicio de su compleja relación.

El gobierno de Perón no dudó en defender el decreto n. 18.411/43. Aún más, en 1947 se procedió a su tratamiento parlamentario para convertirlo en ley nacional. Esa decisión hizo que se evidenciaran las voces disidentes al interior del partido gobernante, que se referenciaban en el laborismo y que, sin dejar de reivindicar al cristianismo, despotricaban contra lo que entendían como una versión reaccionaria del catolicismo. La conformación heterogénea de las bases políticas del naciente peronismo hizo que, por ejemplo, trece de los diputados peronistas se negaran a realizar el juramento por los Santos Evangelios al asumir sus bancas en 1946 (Di Stéfano, 2010). A la hora de la votación por la ratificación de la educación religiosa obligatoria, muchos de esos diputados decidieron ausentarse o retirarse antes de la votación, favoreciendo la sanción de una ley que el mismo Perón se había encargado de asegurar, dando instrucciones de procedimiento a sus legisladores (Caimari, 2010, p. 161).

Tras largos debates parlamentarios, la ley fue finalmente aprobada en abril de 1947. Su implementación puso prontamente en evidencia la tensión latente entre el peronismo y la Iglesia católica. Las disputas por la dirección tanto administrativa como pedagógica de la educación religiosa en las escuelas públicas supuso el enfrentamiento entre dos actores políticos que "compartían una vocación hegemónica" (Ghio, 2007, p. 137) y que hicieron de la educación un campo de batalla por la consolidación y expansión de su poder al resto de la sociedad. Ya desde la reglamentación de la ley en noviembre de 1947, el gobierno marcó el lugar que ocuparía la Iglesia al disponer que la Dirección General de Instrucción Religiosa estaría compuesta por seis miembros: un director y cuatro vocales designados por el gobierno, y el restante sería designado por el Episcopado. Con la creación de la Secretaría de Educación en 1948, se sucedería también la degradación de la Dirección de Instrucción Religiosa a la categoría de Departamento (Bianchi, 1992; Caimari, 2010).

La Iglesia debió enfrentar además la falta de una disposición suficiente de docentes para la materia así como su deficiente formación. Pero fundamentalmente, la Iglesia debió enfrentarse al proceso de peronización de la enseñanza (Bianchi, 1992) que suponía una creciente disolución del discurso católico dentro del nuevo discurso peronista. Las prácticas escolares y disposiciones curriculares que exaltaban un sentimiento de devoción hacia las figuras de Perón y Evita amenazaban con desplazar al discurso católico que había ocupado un espacio central en las escuelas desde la denominada Década Infame (1930-1943) (Bertetti; Puiggrós, 1993, p. 338).

Dentro de este período, debe hacerse referencia también a la ley n. 13.047, de 1947, que creó el Estatuto para el Personal Docente de los Establecimientos Privados de Enseñanza. Se normativizó así el funcionamiento de esas instituciones y se equipararon los derechos y obligaciones de los docentes privados a aquellos de los docentes bajo la órbita del Estado, incluido el establecimiento del salario mínimo. Este reconocimiento marcó un hito en la construcción del sistema educativo argentino, pues dejó sentada la responsabilidad del Estado en el financiamiento del sector educativo privado. Se creó también una clasificación de los establecimientos privados en "adscriptos a la enseñanza oficial", "libres" y "establecimientos privados de enseñanza en general" (ley n. 13.047, art. 
$\left.2^{\circ}\right)$. Este reconocimiento normativo que dispuso un conjunto de mejoras para el sector privado implicó para la Iglesia, sin embargo, un mayor control estatal sobre su actividad, al igual que había sucedido con la educación religiosa y que ahora también reavivaba las tensiones en las escuelas católicas.

Finalmente, en medio de los crecientes enfrentamientos políticos entre el peronismo y la Iglesia, en 1954 se derogó la ley de enseñanza religiosa obligatoria. Como señala Caimari: "A pesar de las perspectivas radiantes, la experiencia de la religión en las escuelas fue decepcionante para los católicos" (2010, p. 167). Esta decepción, dada entre las cesiones y tensiones con el peronismo, llevó a un punto de quiebre en la estrategia de la Iglesia, que advirtió los límites de una educación religiosa bajo el control del Estado y con docentes poco preparados y pasó a centrarse en los años siguientes en la construcción de un sector educativo alternativo y autónomo.

\section{5-1976: consolidación de la educación privada}

Con el derrocamiento militar de Perón, la Iglesia volvió a configurar su posicionamiento frente a las autoridades en el gobierno. La denominada Revolución Libertadora contó con la Iglesia católica como uno de sus principales aliados. En este nuevo contexto, el nacionalista católico Atilio Dell'Oro Maini, ministro de Educación del gral. Pedro Aramburu, promulgó a fines de 1955 un decreto de organización de las universidades nacionales. La crisis fue generada por el artículo 28 que autorizaba la creación de universidades privadas facultadas para la emisión de títulos profesionales habilitantes. Las movilizaciones estudiantiles en oposición pronto coparon las calles. Es conocido también el pronunciamiento público del entonces rector de la UBA, José Luis Romero, quien identificó como "educación religiosa lo que en la letra del decreto era llamada simplemente como educación "libre" (Di Stéfano, 2010, p. 367). Las disputas por esta normativa sintetizadas como la polémica entre laica o libre fueron abruptamente acalladas con la renuncia del ministro en mayo de 1956, dejando abierta su reglamentación al próximo gobierno. Es así que el enfrentamiento volvería a surgir en 1958 durante la presidencia de Arturo Frondizi.

Resumidamente, tras la propuesta de Frondizi de convertir en ley al discutido artículo, se iniciaron masivas movilizaciones no sólo por parte de quienes se oponían al decreto, sino también de aquellos católicos que se sentían agraviados por el tono anticlerical que habían tomado las discusiones. La intensidad de la protesta contra la sanción de esta ley incluyó tomas de escuelas y facultades por parte de estudiantes secundarios y universitarios, así como la movilización de otros actores políticos como sindicatos de docentes y de otras ramas productivas. En ello se ponía en discusión un conjunto de significados que iban más allá de la cuestión universitaria. La polémica laica o libre reactualizó las disputas históricas que tenían en su centro las pretensiones de la Iglesia de catolizar a la sociedad, incluido el campo educativo como principal ámbito de injerencia, frente a las reivindicaciones de un discurso educativo laicista que había buscado dar sentido al sistema escolar público desde su formación.

La represión del gobierno aplacó las protestas callejeras y permitió finalmente que se sancionara la ley n. 14.557, conocida como Ley Domingorena. Junto al reconocimiento otorgado a las universidades privadas se sucedió un cambio de estrategia en la Iglesia, que había notado las deficiencias de una enseñanza religiosa obligatoria dentro del 
sistema educativo público en relación a los beneficios que podrían derivarse de la consolidación de un circuito educativo propiamente católico, separado de la gestión estatal.

La década del 1960 estuvo marcada por las transformaciones y disputas al interior del catolicismo a partir del Concilio Vaticano II (1962-1965). En materia educativa, la encíclica Gravissimum Educationis, de 1965, desplazándose de los postulados preconciliares centrados en la lucha enfática contra el liberalismo, renovó la visión católica respecto al rol principal de los padres y la Iglesia como educadores, y la consecuente subsidiariedad estatal. En articulación con este nuevo marco doctrinario, la revitalización de la Iglesia argentina fue de la mano de la consolidación del sector educativo privado, mayoritariamente católico. El avance sostenido de la participación relativa del sector privado en el sistema educativo nacional, para el periodo 1962-1976 se evidencia en la tasa de crecimiento de la matrícula privada de 85\% (de 303.648 a 561.306 alumnos) frente a una tasa de $22 \%$ (de 1.441 .559 a 1.761 .423 alumnos) correspondiente al sector estatal (Bravo, 1984:38).

Este crecimiento del sector educativo privado se acompañó de una estructura normativa y administrativa específica (Perazza; Suárez, 2011). Además del ya existente estatuto para los docentes privados promulgado por Perón, en 1958 se creó dentro de la órbita del Ministerio de Educación la Superintendencia Nacional de Educación Privada, cuyos primeros funcionarios fueron promovidos por la propia Iglesia. Durante la presidencia de Arturo Illia se reglamentaron las proporciones de la subvención estatal para el pago de los salarios docentes, que cubría desde el $40 \%$ hasta el $100 \%$ y quebraba con la discrecionalidad que había regido hasta el momento (Morduchowicz; Iglesias, 2011). También se reglamentó la incorporación de los institutos privados a la enseñanza oficial, concretamente las instituciones privadas de nivel secundario y superior.

Ese lugar preeminente de la Iglesia en el espacio público sería confirmado con la dictadura de Juan Carlos Onganía (1966-1970), incluso en su fluctuante vínculo con el catolicismo (Zanca, 2014). El segundo de los ministros de Educación de Onganía, José Astigueta, se rodeó de un grupo de especialistas católicos que compartían redes de sociabilidad, y que ocuparon distintos cargos dentro del Ministerio (Rodríguez, 2013a). Parte de ese equipo elaboró en 1968 anteproyectos de leyes nacionales de educación donde se establecía la distinción entre educación pública estatal y educación pública no estatal (Bravo, 1991), buscando incluir de ese modo a las escuelas privadas como parte de lo público.

Los inicios de la década del 1970 estarían marcados igualmente por el lugar de la Iglesia católica como un actor necesario de consulta con poder de veto en las decisiones gubernamentales referidas especialmente al sector educativo privado. En el tercer gobierno peronista (1973-1976) se puso en discusión el lugar de la Iglesia católica como actor del sector educativo privado. Se sucedieron debates en torno a la regulación normativa del aporte estatal a las escuelas privadas y la regulación del trabajo docente en ellas. Finalmente, en los hechos, el gobierno peronista terminó ratificando los términos de la ley n. 13.047/47, asegurando los aportes estatales y legitimando el estatuto administrativo de los establecimientos privados (Rodríguez, 2013b).

El apoyo de los distintos gobiernos a la expansión de la educación privada en este periodo marca el pasaje de un Estado nacional netamente educador a un Estado 
subsidiario. En todo este periodo se sentaron las bases para el fortalecimiento - en términos normativos, institucionales y financieros - de ese sector. Dejando atrás, aunque nunca totalmente, los clamores por la inclusión de la educación religiosa en las escuelas públicas, se consolidaba la estrategia de la Iglesia tendiente a la construcción de un espacio educativo propio sobre el fundamento de la libertad de enseñanza.

\section{6-1983: dictadura, catolicismo y represión}

El golpe militar encabezado por el gral. Jorge Videla en 1976 profundizó el vínculo sincrético entre las Fuerzas Armadas y las pretensiones catolizantes de la Iglesia argentina. Este proceso se combinó con una estructura fuertemente reaccionaria y represiva, lo que supuso que el ámbito educativo se convirtiera para la dictadura en unos de los puntos de ataque primordiales contra la amenaza subversiva. A diferencia de lo que había sucedido en otros periodos, esta vez la Iglesia argentina no debió presionar o negociar para que sus requerimientos se hicieran presentes en la definición de las políticas educativas, porque los militares en el gobierno dieron por sentada su alianza con la versión más conservadora del catolicismo. Era precisamente la Iglesia católica la que sugería al gobierno de manera vinculante los nombres de los funcionarios del Ministerio de Educación, quienes provenían de la intelectualidad católica pre-conciliar anclada en instituciones como el Consucec, la UCA o la Acción Católica.

En términos de las políticas educativas del autodenominado Proceso de Reorganización Nacional, Pineau (2006) distingue dos estrategias del régimen militar. Por un lado, una estrategia represiva y, por el otro lado, una estrategia discriminadora. La estrategia represiva consistió en un restablecimiento de los valores perdidos en el sistema educativo y el consecuente silenciamiento de voces disidentes. Este enfoque estaba fundamentado en una versión del ser nacional que lo ligaba de manera esencial con la civilización occidental y cristiana, así como al orden y el respeto a las autoridades. El disciplinamiento del sistema educativo devino así en el secuestro y desaparición de estudiantes y docentes, cesantías forzadas, censura de libros, y otras formas de autoritarismo en las prácticas cotidianas. $Y$ también, en otro plano, en el combate a las ideas pedagógicas progresistas que habían emergido en décadas pasadas.

Más allá de las particularidades de la gestión de cada uno de los cinco ministros de educación de la dictadura (Rodríguez, 2011; Tedesco; Braslavsky; Carciofi, 1987), sus lineamientos educativos tuvieron como nudos de sentido la subsidiariedad estatal, el elitismo, y la defensa de la tradición católica de la nacionalidad argentina, la moral cristiana, la familia y el valor de la trascendencia espiritual en la concepción del hombre. El gobierno militar no incluyó la educación religiosa obligatoria como una materia específica sino que fue más allá, al incluir una perspectiva católica que atravesó la definición de los lineamientos curriculares, lo que se hizo palpable en materias como Estudios Sociales en el nivel primario, y en Historia y Formación Moral y Cívica en el nivel secundario.

En cuanto a la estrategia discriminadora de la dictadura, ella consistió en la desarticulación del sistema educativo nacional, generando la progresiva descentralización del sistema y el avance del sector privado. El efecto a mediano plazo fue una segmentación inequitativa del sistema educativo en circuitos diferenciados según las regiones y los sectores socio-económicos de pertenencia de los estudiantes (Braslavsky 
1985). El primer ministro de Educación de la dictadura, Ricardo Bruera, dispuso el traspaso de las escuelas nacionales a las provincias para reducir el gasto educativo del Estado nacional. Este desplazamiento del Estado nacional como principal responsable del financiamiento educativo público se articulaba con la subsidiariedad que la Iglesia propugnaba como base del sistema educativo y la consecuente transferencia de recursos al sector privado. El ministro Llerena Amadeo, en uno de sus discursos públicos, señalaba que el Estado debía "asegurar la vigencia de la escuela privada", a la vez que, en un sentido muy importante para lo que sucedería en las décadas siguientes, fundía en el término "enseñanza pública" tanto a las escuelas estatales como a las privadas (Rodríguez, 2011, p. 73).

A pesar del fuerte ambiente represivo de este periodo, el avance de la catolización del sistema educativo tuvo también algunos focos de disenso. Uno de los puntos de discusión pública fue la instauración de la materia Educación Moral y Cívica en 1978, que fue vista por algunos sectores como un modo solapado de volver a la educación católica obligatoria. Ante esta disposición, desde la Delegación de Asociaciones Israelitas Argentinas se emitió una declaración donde, en virtud de la defensa de la libertad de conciencia, se objetaban los contenidos de la materia sosteniendo que en ella "inculcaba nociones y conceptos propios de una religión que podía ser ajena a determinados educandos" (Rodríguez, 2011, p. 90). De igual modo, surgieron pronunciamientos por parte de asociaciones como la Liga Argentina de Cultura Laica y la Convención Evangélica Bautista. Además de estos cuestionamientos a la pretensión de universalidad del catolicismo, dentro de los propios colegios católicos emergieron disensos con el régimen dictatorial (Mignone, 1999).

La estrategia de represión a las posibles infiltraciones subversivas también los incluyó, especialmente en aquellas instituciones donde se habían recibido de buen modo los postulados del Concilio Vaticano II y la Conferencia Episcopal Latinoamericana de Medellín. En el marco del Operativo Claridad impulsado por el ministro Bruera en 1976 se inició la persecución de docentes y estudiantes así como la intervención de muchos colegios. Entre ellos, hubo algunos establecimientos privados católicos. En agosto de 1979 el gobierno nacional promulgó la ley n. 21.381 que facultaba al Ministerio de Educación a la inhabilitación y despido de aquel personal de establecimientos privados que se encontrara "vinculado a actividades subversivas" (citado en Mignone, 1999, p. 154).

El proyecto educativo dictatorial avanzó sobre los sentidos de gratuidad y laicidad del sistema educativo nacional, desde los argumentos integralistas puestos en juego, las propuestas educativas, las normativas sancionadas y las políticas desarrolladas. El descrédito del Estado como responsable educativo abrió el lugar a la relegitimación de la Iglesia católica como actor político dentro del sistema educativo. Con mayor énfasis en este periodo, la educación pública dejó de estar asociada de manera lineal a lo estatal. A esto debe sumarse la impronta moralista, represiva y autoritaria que atravesó el sistema educativo, características que serían puesta en discusión con el regreso de la democracia. 


\section{3-1989: democracia, educación y memoria laicista}

Con el retorno de la democracia en 1983, y tras el embate de las políticas de la dictadura contra los nudos de sentido que habían fundado el sistema educativo nacional, los esfuerzos del gobierno de Ricardo Alfonsín se centraron, como señala Southwell, en "restablecer el canon clásico del sistema educacional, más que generar uno nuevo" (2007, p. 316). El espacio fundamental para poner en discusión los sentidos de la educación pública fue el Congreso Pedagógico Nacional - CPN, convocado mediante la ley n. 23.114 de septiembre de 1984, y cuyos debates se extendieron entre abril de 1986 y marzo de 1988. El CPN hizo un llamado abierto a la participación de la comunidad educativa, gremios, partidos políticos y organizaciones sociales, en la búsqueda de generar consensos para la elaboración y sanción de una ley que reformara el sistema educativo.

Era innegable que el sentido que se le daba a este Congreso remitía a la memoria de las discusiones de fines del siglo 19 y al lema de la obligatoriedad, la gratuidad y la laicidad de la ley n. 1.420. El laicismo que atravesó esas discusiones había significado una herida para la Iglesia católica que arrastró a lo largo de todo el siglo, de modo que ahora se le presentaba una nueva oportunidad de poder convertirse en una indiscutida protagonista de la definición de los lineamientos educativos del país. A pesar de que en un principio se mostró reticente, la Iglesia se aseguró la movilización del espectro de actores católicos, en una actitud defensiva frente a lo que algunos de los miembros de la Conferencia Episcopal Argentina percibían como una amenaza laicista del gobierno (Krotsch, 1988; Fabris, 2011). Para ello, la Iglesia realizó un llamado masivo a la participación activa de las familias, clérigos y docentes ligados a las parroquias y escuelas católicas con el fin de copar las asambleas descentralizadas de discusión del CPN y defender la denominada enseñanza libre, el derecho de los padres como primeros educadores y la autonomía pedagógica y administrativa de las instituciones educativas confesionales.

Además de dominar en gran parte las discusiones en el marco del CPN, en distintos documentos del Episcopado centrados en los procesos políticos y sociales de la Argentina democrática, la cuestión educativa tuvo un lugar central. El principal trabajo presentado como estrategia de disputa en las discusiones de este periodo fue el documento Educación y proyecto de vida, redactado por el Equipo Episcopal de Educación Católica en 1985. Ese documento se elaboró como aporte a la discusión pública sobre el sistema educativo nacional y sirvió para poner nuevamente en escena sus concepciones críticas acerca del rol del Estado, la defensa de la educación religiosa, sin dejar de incluir una presión explícita por el financiamiento del sector educativo privado.

A este respecto, resulta interesante destacar también las denominaciones que se le daban a los emprendimientos privados bajo la órbita de la Iglesia católica. En algunos documentos eclesiásticos fundamentales elaborados al albor de la democracia, la Iglesia propuso distintas denominaciones tales como establecimientos educacionales no oficiales, enseñanza pública no oficial o enseñanza libre como alternativas a la denominación enseñanza particular o privada. La Iglesia fue construyendo así, en un terreno de disputas con el discurso educativo estatal, un nuevo sentido para la educación del sector privado desplazándolo hacia su inclusión dentro de la esfera educativa pública.

Sin dejar de defender la educación religiosa en las escuelas, uno de los puntos de interés para la Iglesia católica fue principalmente la equiparación de lo privado con lo 
público - en tanto común y no como sinónimo de estatal. El análisis de la multiplicidad de sentidos en disputa en torno al carácter público de la educación en la década del 1980 muestra las controversias por lo que a partir de la sanción de la Ley Federal de Educación en 1993 se impondría como educación pública de gestión privada.

\section{9-2001: neoliberalismo y educación pública de gestión privada}

Muchas de las conclusiones del CPN sirvieron como antecedente inmediato para la definición de la reforma educativa impulsada por el gobierno de Carlos Menem a principios de la década del 1990. En el marco de la redefinición de los sentidos históricos asignados a la educación pública, las aspiraciones de la Iglesia católica como referente principal del sector educativo privado se materializaron, como ya había sucedido en otros periodos, en las bases legales del propio sistema educativo. En el contexto de los buenos vínculos de la institución eclesiástica con el gobierno menemista, la Ley Federal de Educación, n. 24.195, sancionada en 1993 incluyó dentro de la educación pública a los establecimientos de gestión privada junto a los de gestión estatal, además de reconocer explícitamente el rol educador de la Iglesia. Principalmente, este cambio supuso una nueva impugnación del papel que históricamente había desempeño el Estado en materia educativa dentro de un modelo político y educativo tendiente a la privatización de lo público.

Junto con este reconocimiento normativo, la Iglesia argentina pudo retornar a espacios de decisión educativa dentro de la estructura del Estado. Su aval para el nombramiento de los funcionarios del Ministerio de Educación volvió a convertirse en moneda corriente. De igual modo, la Dirección de Educación Privada se asentó como el espacio reservado para individuos provenientes de las redes intelectuales católicas. Además de controlar los lineamientos educativos del sector privado desde adentro, la cúpula de la Iglesia se erigió en consultora privilegiada del resto de decisiones educativas a cargo del gobierno. El caso más destacable en este periodo fue la definición de los denominados Contenidos Básicos Comunes según los términos de la reforma educativa. Distintos obispos intervinieron directamente solicitando al entonces Ministro de Educación la inclusión de elementos axiológicos y conceptuales propios de la doctrina católica, tales como las referencias a Dios, la trascendencia espiritual como dimensión constitutiva de lo humano, la primacía de la familia y el rol protagónico del catolicismo en la historia universal (Esquivel, 2004; Nosiglia; Zaba, 2003). Para satisfacción de la Iglesia, esos elementos fueron efectivamente incluidos dentro de la propuesta curricular oficial.

El desplazamiento del Estado nacional como principal responsable de la educación legitimó el accionar de la Iglesia católica. Ello supuso la lucha por los subsidios de un Estado que, en la visión de la Iglesia, no debía regir monopólicamente pero sí financiar al conjunto de la educación pública. La influencia del catolicismo en la definición de las políticas curriculares nacionales no dejó de hacerse sentir, aunque también en este periodo su foco de intervención pública estuvo puesto en la consolidación del conjunto de establecimientos educativos católicos, tendiendo así a su relativa autonomización dentro del sistema educativo nacional. 


\section{Conclusiones y perspectivas}

En este trabajo nos centramos en la relación entre la Iglesia católica y el campo educativo argentino, a nivel nacional. Si, como señala Poulat (1986) la Iglesia es un mundo, el rápido recorrido por cinco siglos de relación con lo educativo debe reconocer la multiplicidad de configuraciones institucionales de la propia Iglesia, así como la diversidad de catolicismos, y las prácticas, símbolos, imaginarios, éticas así como grupos, movimientos sociales y subjetividades que los sustentan (Mallimaci, 1992; Mallimaci y Esquivel, 2013). Lo mismo vale decir para la configuración del sistema educativo y la diversidad de actores, prácticas e imaginarios englobados en él.

Sintéticamente, puede decirse que la configuración actual del campo educativo argentino es el resultado tanto de los lineamientos normativos así como de la cultura política heredada a lo largo de una historia de tensiones, disputas y reconocimientos entre el Estado y la Iglesia católica. Incluso la actual Ley Nacional de Educación, n. 26.206, sancionada en 2006 como parte del embate crítico contra las políticas educativas neoliberales de la década anterior, normativiza y legitima cuestiones que fueron objeto de controversia en las décadas pasadas. Esta ley retoma la distinción de la educación pública según tipos de gestión, el lugar de la Iglesia como agente educativo con derecho a la emisión de títulos propios y el aporte financiero del Estado a los salarios de los docentes de establecimientos privados.

También en las constituciones provinciales se hace evidente la actualidad de las tensiones heredadas por la laicidad educativa. Por ejemplo, las constituciones de Salta, Tucumán, Santiago del Estero y Córdoba contemplan la enseñanza religiosa obligatoria en las escuelas públicas, mientras que en La Pampa y San Luis se establece que la enseñanza de la religión puede ser impartida por los ministros autorizados de los diferentes cultos, aunque por fuera del horario de clase. La impronta confesional está en el fundamento de las constituciones de Buenos Aires, Córdoba, Catamarca y Tucumán, donde la definición de los fines educativos incluye la dimensión trascendente como parte de la formación integral de la persona (Esquivel, 2010b). Ello se articula con la marcada participación del sub-sector confesional dentro del sector educativo privado, con un promedio nacional de 64\% para 2005 y con picos cercanos al $90 \%$ en provincias como Córdoba, La Pampa o Santa Cruz (Rivas, 2009, p. 80). Consecuentemente, otro elemento a destacar es la aplicación dispar del Programa Nacional de Educación Sexual Integral, instituido en 2006 en medio de disputas por su definición frente a la marcada negativa de la Iglesia católica (Esquivel, 2013).

Dentro de un contexto democrático marcado por el progresivo desplazamiento de la Iglesia católica en la definición de políticas nacionales, en tensión con sus mandatos doctrinales - tales como las leyes de divorcio, salud sexual y reproductiva, educación sexual obligatoria, matrimonio igualitario, identidad de género, muerte digna, fertilización asistida, además de las discusiones sobre la despenalización del aborto en el Congreso de la Nación - la educación se constituye en un reducto privilegiado de resistencia e intervención dentro del espacio público frente a un Estado que, sin dejar de privilegiar a la institución eclesiástica, avanza en un sentido diferente frente a las demandas católicas.

En el recorrido histórico de este trabajo se identificaron líneas de continuidad, discontinuidad y resistencia en los distintos periodos a la vez que se destacaron los posicionamientos discursivos de la Iglesia sobre la cuestión educativa. Ello abre 
finalmente una vía de entrada teórico-metodológica para el estudio de la laicidad y el lugar de la Iglesia católica en el campo educativo. Siguiendo la perspectiva de Foucault, el discurso "no es simplemente aquello que traduce las luchas o los sistemas de dominación, sino aquello por lo que, y por medio de lo cual se lucha" (2004, p. 15). Si se asume además que el discurso, en tanto práctica social, constituye "una esfera de hegemonía cultural" (Fairclough, 1995, p. 95), puede resultar fructífero el análisis de la construcción histórica de un orden discursivo propiamente católico como parte de una configuración hegemónica donde se producen, reproducen, desafían y transforman los posicionamientos políticos de la Iglesia y el Estado por el gobierno de la educación.

Al emprender una mirada de largo plazo, en este trabajo no pueden abordarse los necesarios matices y especificidades de cada período histórico. Frente a este panorama, el cierre de este trabajo es necesariamente una puerta abierta, por un lado, al devenir de las relaciones entre la Iglesia católica, el Estado y el campo educativo y, por el otro lado, a la ampliación y profundización de la investigación y discusión sobre esos vínculos desde una perspectiva histórica, sociológica y educativa.

\section{Referencias}

BERNETTI, Jorge y PUIGGRÓS, Adriana. Peronismo: cultura política y educación (19451955). Buenos Aires: Galerna, 1993

BIANCHI, Susana. Iglesia católica y peronismo: la cuestión de la enseñanza religiosa. Estudios Interdisciplinarios de América Latina y el Caribe, Tel Aviv: Facultad de Humanidades Lester y Sally Entin, v. 3, n. 2, 1992, p. 89-103.

BLANCARTE, Roberto. El porqué de un Estado laico. En: BLANCARTE, Roberto (coord.). Los retos de la laicidad y la secularización en el mundo contemporáneo. México: El Colegio de México, 2008a, p. 29-46.

BLANCARTE, Roberto. Laicidad y laicismo en América Latina. Estudios Sociológicos, México: El Colegio de México, v. 26, n. 76, 2008b, p. 139-164.

BLANCARTE, Roberto. ¿Cómo podemos medir la laicidad? Estudios Sociológicos, México: El Colegio de México, v. 30, n. 88, 2012, p. 233-247.

BRASLAVSKY, Cecilia. La discriminación educativa en Argentina. Buenos Aires: Miño y Dávila, 1985.

BRAVO, Héctor. El estado y la enseñanza privada. Buenos Aires: De Belgrano. 1984.

BRAVO, Héctor. La transformación educacional. Buenos Aires: Corregidor, 1991.

BRITO, Horacio. La organización de la Iglesia. En AAVV. 500 años de cristianismo en Argentina. Buenos Aires: Centro Nueva Tierra-Cehila, 1992, p. 61-110.

CAIMARI, Lila. Perón y la iglesia católica. Buenos Aires: Emecé, 2010.

CASANOVA, José. Public religions in the modern world. Chicago: The University of Chicago Press, 1994.

CASANOVA, José. Genealogías de la secularización. Barcelona: Anthropos, 2012.

DI STEFANO, Roberto. Ovejas negras. Buenos Aires: Sudamericana, 2010. 
DI STEFANO, Roberto. Por una historia de la secularización y de la laicidad en la Argentina. Quinto Sol, La Pampa: UNLPam, v. 15, n. 1, 2011, p. 1-32.

DI STEFANO, Roberto; ZANATTA, Loris. Historia de la iglesia argentina. Buenos Aires: Sudamericana, 2009.

DRI, Rubén. Proceso a la iglesia argentina. Buenos Aires: Biblos, 1997.

ESQUIVEL, Juan. Detrás de los muros. Bernal: UNQ, 2004

ESQUIVEL, Juan. Los espacios de laicidad en el Estado argentino. CONGRESS OF THE LATIN AMERICAN STUDIES ASSOCIATION. 2010a, Toronto.

ESQUIVEL, Juan. La preponderancia católica en la legislación nacional y provincial. Nueva Tierra, Buenos Aires: Centro Nueva Tierra, 2010b, p. 56-56. Recuperado de: <http://www.nuevatierra.org.ar/-2010/10/248>.

ESQUIVEL, Juan. Cuestión de educación (sexual): pujas y negociaciones políticoreligiosas en la Argentina democrática. Buenos Aires: Clacso, 2013.

FABRIS, Mariano. Iglesia y democracia. Rosario: Prohistoria, 2011.

FAIRCLOUGH, Norman. Critical discourse analysis. Londres: Longman, 1995.

FOUCAULT, Michel. El orden del discurso. Buenos Aires: Tusquets, 2004.

GHIO, José. La iglesia católica en la política argentina. Buenos Aires: Prometeo, 2007.

KROTSCH, Carlos. Iglesia, educación y congreso pedagógico nacional. In: EZCURRA, Ana. Iglesia y transición democrática. Buenos Aires: Puntosur, 1988, p. 203-250.

LIBOREIRO, María. La evangelización en la colonia. En: AAVV. 500 años de cristianismo en Argentina. Buenos Aires: Centro Nueva Tierra-Cehila, 1992, p. 15-60.

MALLIMACI, Fortunato. El catolicismo integral en la Argentina (1930-1946). Buenos Aires: Biblos.

MALLIMACI, Fortunato. El catolicismo argentino desde el liberalismo integral a la hegemonía liberal. En: AAVV. 500 años de cristianismo en Argentina. Buenos Aires: Centro Nueva Tierra-Cehila, 1992, 197-365.

MALLIMACI, Fortunato. Catolicismo y liberalismo: las etapas del enfrentamiento por la definición de la modernidad religiosa en América latina. En: BASTIAN, Jean-Pierre (coord.). La modernidad religiosa: Europa Latina y América Latina en perspectiva comparada. México: FCE, 2004, p. 19-44.

MALLIMACI, Fortunato. Religión, política y laicidad en la Argentina del siglo XXI. En: DA COSTA, Néstor (org.). Laicidad en América Latina y Europa. Montevideo: Claeh-Alfa, 2006, p. 71-80.

MALLIMACI, Fortunato. Excepcionalidad y secularizaciones múltiples. In: MALLIMACI, Fortunato (ed.). Religión y política. Buenos Aires: Biblos, 2008, p. 117-137.

MALLIMACI, Fortunato; ESQUIVEL, Juan. La tríada Estado, instituciones religiosas y sociedad civil en la Argentina contemporánea. Amerika. Mémoires, identités, territoires, v. 8, 2013. Recuperado de: <http://amerika.revues.org/3853>.

MIGNONE, Emilio. Iglesia y dictadura. Bernal: UNQ, 1999. 
MORDUCHOWICZ, Alejandro; IGLESIAS, Gustavo. Auge y avance de los subsidios estatales al financiamiento de las escuelas privadas en la Argentina. In: PERAZZA, Roxana (coord.). Mapas y recorridos de la educación de gestión privada en la Argentina. Buenos Aires: Aique, 2011, p. 131-164.

NOSIGLIA, María; ZABA, Stella. El papel de la Iglesia católica en la formulación e implementación de las políticas educativas argentinas en los 90. Anuario de Historia de la Educación, Buenos Aires: Sahe, v. 3, n. 4, 2003, p. 61-93.

PERAZZA, Roxana; SUÁREZ, Gerardo. Apuntes sobre la educación privada. En: PERAZZA, Roxana (coord.). Mapas y recorridos de la educación de gestión privada en la Argentina. Buenos Aires: Aique, 2011, p. 25-56.

PINEAU, Pablo. El principio del fin. Buenos Aires: Colihue, 2006.

POULAT, Emile. L’Eglise, c’est un monde. París: Cerf, 1986.

POULAT, Emile. Nuestra laicidad pública. México: FCE, 2012.

PUIGGRÓS, Adriana. Sujetos, disciplina y currículum en los orígenes del sistema educativo argentino. Buenos Aires: Galerna, 1990.

PUIGGRÓS, Adriana. Qué pasó en la educación argentina. Buenos Aires: Galerna. 2012.

RIVAS, Axel. Lo uno y lo múltiple. Buenos Aires: Academia Nacional de Educación. 2009

RODRÍGUEZ, Laura. Católicos, nacionalistas y políticas educativas en la última dictadura (1976-1983). Rosario: Prohistoria, 2011.

RODRÍGUEZ, Laura. Los católicos desarrollistas en Argentina. Diálogos. Maringá: UEM, v. 17, n. $1,2013 a$, p. 155-184.

RODRÍGUEZ, Laura. Los católicos y la educación en el tercer peronismo (1973-1976). Anuario de Historia de la Educación. Buenos Aires: Sahe, v. 14, n. 2, 2013b, p. 1-16.

ROITENBURD, Silvia. Educación y control social: el nacionalismo católico cordobés (1862-1944). En: PUIGGRÓS, Adriana (dir.). La educación en las provincias y territorios nacionales (1885-1945). Buenos Aires: Galerna, 1993, p. 59-119.

SOUTHWELL, Myriam. Con la democracia se come, se cura y se educa: disputas en torno a la transición y las posibilidades de una educación democrática. En: CAMOU, Antonio, TORTTI, Cristina y VIGUERA, Aníbal (coords.). La Argentina democrática: los años y los libros. Buenos Aires: Prometeo, 2007, p. 307-334.

TEDESCO, Juan. Educación y sociedad en la Argentina (1880-1945). Buenos Aires: Siglo XXI, 2003.

TEDESCO, Juan, BRASLAVSKY, Cecilia; CARCIOFI, Ricardo (org.). El proyecto educativo autoritario: Argentina 1976-1982. Buenos Aires: Flacso-Miño y Dávila, 1987.

ZANATTA, Loris. Del estado liberal a la nación católica. Bernal: UNQ, 1996.

ZANCA, José. Más allá de la espada y el hisopo. Religión, política y sociedad durante el onganiato. En: GALVÁN, María; OSUNA, María (comps.). Política y cultura durante el onganiato. Rosario: Prohistoria, 2014, p. 29-46. 
GERM ÁN TORRES es licenciado en Educación (Universidad Nacional de Quilmes), máster en Investigación Aplicada a la Educación (Universidad de Valladolid). Becario doctoral en el Programa Sociedad, Cultura y Religión del Centro de Estudios e Investigaciones Laborales, Conicet y en el Departamento de Ciencias Sociales de la Universidad Nacional de Quilmes.

Endereço: Saavedra 15, piso 4으- Buenos Aires - Argentina.

E-mail: germansmt@yahoo.com.ar.

Recebido em 5 de outubro de 2013.

Aceito em 12 de março de 2014 